Bidwell', who suggests that the abnormality may be caused by a gradual breakdown of the lattice as the melting point is approached. In support of this hypothesis he quotes observations ${ }^{2}$ which tend to show that the X-ray diffraction patterns disappear also well below the melting point.

Whatever the cause of the phenomenon, we wish to emphasize that, so far as present knowledge goes, it is an effect which is characteristic of the alkali metals, since it is almost absent in other elements, for example, mercury ${ }^{3}$, bismuth ${ }^{4}$, iodine ${ }^{5}$ and lead ${ }^{6}$, on which measurements of true specific heat have been made right up to the melting point.

\section{G. Carpenter.}

T. F. Harle.

C. J. STEWARD.

Physical Laboratory,

University College,

Southampton. April 13.

1 Bidwell, Phys. Rev., 28, 584 (1926).

¿ Bidwell, Phys. Rev., 27, 381 (1926).

${ }^{3}$ Carpenter and Stoodley, Phil. Mag., 10, 249 (1930).

- Carpenter and Harle, Proc. Roy. Soc., A, 136, 243 (1932).

sarpenter and Harle, Phil. Mag., 22, 193 (1937).

- Klinkhardt, Ann. Phys., 84, 167 (1927).

\section{Free Field Calibration of Microphones}

The determination of the 'field calibration' of a microphone, that is, the sensitivity under free space conditions, has been rendered difficult in the past by the presence of air currents comparable with the velocities to be measured, or field irregularities and uncertainties in direction due to reflection from the walls in a small enclosure. If, in the case of a pressure operated microphone, one tries to avoid this trouble by determining the pressure calibration by the resonant tube ${ }^{1}$ or thermophone methods and by calculating the increase in sensitivity due to reflection from the microphone, the difficulty, if not impossibility, of making this calculation rigidly for practical forms of microphone is encountered.

We have developed a new technique of calibration by substitution in the free field, using a search tube of small diameter connected to a condenser microphone. The free space calibration of this search tube is obtained by inserting its open end through a rubber bush in one end of a closed resonant tube and adjusting its position until it is one or more half wavelengths from the bush, that is, until it is at a pressure maximum other than those occurring at the two ends of the resonant tube. The search tube is then in a standing wave, which is conveniently measured by a Rayleigh disk suspended at the centre of the resonant tube. We have shown experimentally that the response of the search tube microphone is dependent only on the acoustic pressure at its mouth and is independent of the diameter of the resonant tube so long as this is large compared with the diameter of the search tube. We have been unable to detect any distortion of a sound field from a loud speaker in an absorbent test room due to the presence of the search tube, so it may be used to explore the field before and after the insertion of the microphone to be calibrated. If this microphone has had a pressure calibration in the resonant tube, the increased sensitivity due to reflection can be deduced. A check on this increase is obtained by a comparison of the explorations of the field with and without the microphone present. This has been done and the variation of the ' $2: 1$ effect' with frequency investigated.

The matter will be dealt with in a paper in the near future.

Research Department,

A. J. KrNG.

C. R. Maguire.

Metropolitan-Vickers Electrical Co., Ltd., Trafford Park, Manchester, 17. May 9.

${ }^{1}$ Churcher, B. G. and King, A. J., J. Inst. Elec. Eng., 68, 97 (1930).

\section{Effect of Manganese Coating on the Magnetic Quality of Iron Wire}

A LENGTH of Armco iron wire was heated in hydrogen at about $1320^{\circ} \mathrm{C}$. until a condition of maximum permeability was reached. The magnetization curve was then obtained (broken line curve in the accompanying graph).

Through the courtesy of Mr. Kenneth Gray, of Messrs. Mellowes and Co., a sample of the same consignment of Armco iron wire was sprayed with a coating of pure manganese powder to a thickness of about 0.002 in. This sample was then heated in hydrogen at about $1320^{\circ} \mathrm{C}$. until a condition of maximum permeability was reached. The magnetization curve was then obtained (full line curve in the graph).

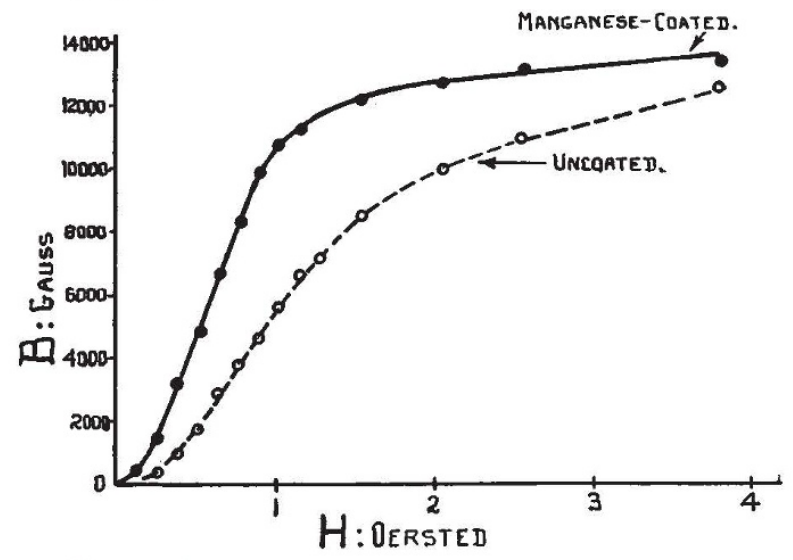

This notable improvement of the magnetic quality of iron wire due to a coating of manganese is all the more surprising when it is recalled that the nonmagnetic quality of Hadfield's manganese steel is due to a 10-15 per cent manganese content, the maximum permeability of this steel being about $\mathbf{1} \cdot 2$. T. F. WALL.

Department of Electrical Engineering,

The University, Sheffield, 1. April 25.

\section{Viscosity of Air and the Electronic Charge}

From measurements of wave-lengths of X-ray lines with ruled grating and from the Bragg angles of reflections from crystals, it is possible to compute the magnitude of the electronic charge. The value thus obtained by Bearden ${ }^{1}$ and Bäcklin ${ }^{2}$ is $4.807 \times 10^{-10}$ E.S.U., which is considerably higher than Birge's ${ }^{3}$ best estimate of Millikan's oil drop value of electronic charge $(4 \cdot 770 \pm 0.005) \times 10^{-10}$ E.S.U. 